Published in final edited form as:

Surg Pathol Clin. 2016 December ; 9(4): 677-684. doi:10.1016/j.path.2016.05.010.

\title{
Analysis of pancreatic cyst fluid
}

\author{
Saowanee Ngamruengphong, MD and \\ Therapeutic Endoscopy Fellow, Division of Gastroenterology and Hepatology, The Johns Hopkins \\ Medical Institutions, Baltimore, MD., 1800 Orleans Street. Sheikh Zayed Tower, Suite M2058., \\ Baltimore, MD 21287 \\ Anne Marie Lennon, MD, PhD \\ Associate Professor of Medicine and Surgery, Division of Gastroenterology and Hepatology, The \\ Johns Hopkins Medical Institutions, Baltimore, MD., 1800 Orleans Street. Sheikh Zayed Tower, \\ Room 7125JB3, Baltimore, MD 21287
}

Saowanee Ngamruengphong: sngamru1@jhmi.edu

\section{Synopsis}

Pancreatic cysts are extremely common, and are identified in between $2 \%$ to $13 \%$ on abdominal imaging studies. The majority of pancreatic cysts are pseudocysts, serous cystic neoplasms (SCNs), mucinous cystic neoplasms (MCNs) or intraductal papillary mucinous neoplasm (IPMNs). The management of pancreatic cysts depends on whether a cyst is benign, has malignant potential, or harbors high-grade dysplasia or invasive carcinoma. The diagnosis of pancreatic cysts, and assessment of risk of malignant transformation, incorporates a number of factors including clinical history, computed tomography (CT), magnetic resonance imaging (MRI), endoscopic ultrasound and fine needle aspiration of cyst fluid (EUS-FNA). This paper reviews the cyst fluid markers which are currently used, as well as promising markers under development.

\section{Keywords}

molecular markers; pancreatic cyst; cyst fluid; intraductal papillary mucinous neoplasm; serous cystadenoma; mucinous cysts

\section{Introduction}

Advances in cross-sectional imaging have resulted in the frequent detection of pancreatic cysts which are incidentally identified in between $2 \%$ to $13 \%$ cases. ${ }^{1,2}$ There are a large number of different types of pancreatic cysts (Table 1), with the most common pancreatic cysts encountered in clinical practice being pseudocysts, serous cystadenomas (SCAs), mucinous cystic neoplasms (MCNs) and intraductal papillary mucinous neoplasm

Corresponding author: Anne Marie Lennon, MD, PhD, Telphone: 410-955-5800, amlennon@jhmi.edu.

Disclosures: Neither Dr. Ngamruengphong nor Dr. Lennon have any disclosures.

Publisher's Disclaimer: This is a PDF file of an unedited manuscript that has been accepted for publication. As a service to our customers we are providing this early version of the manuscript. The manuscript will undergo copyediting, typesetting, and review of the resulting proof before it is published in its final citable form. Please note that during the production process errors may be discovered which could affect the content, and all legal disclaimers that apply to the journal pertain. 
(IPMNs). ${ }^{3}$ The management of pancreatic cysts is very much dependent on the type of pancreatic cyst (Figure 1). ${ }^{4}$ Those with no, or very low malignant potential, such as pseudocysts and SCAs, require minimal or no follow up in the absence of symptoms related to the cyst. ${ }^{5}$ Solid-pseudopapillary neoplasms (SPN) are low-grade malignant neoplasms, and surgically resection is recommended. ${ }^{6}$ Invasive adenocarcinoma occurs in between $4 \%$ to $16 \%$ of surgically resected MCNs in modern studies. ${ }^{7-9}$ Although some groups have recommended that asymptomatic MCNs may be followed ${ }^{10}$, many surgeons favor resection based on the fact that these cysts have the potential for malignant transformation, surgery is curative, and if not undertaken patients require many years of surveillance. ${ }^{11}$ The management of IPMNs depends on whether the main pancreatic duct is involved (main, or mixed-duct IPMN), which is associated with a higher risk of malignant transformation, with high-grade dysplasia or invasive adenocarcinoma identified in between 43 and $62 \%$ of patients who undergo surgical resection. ${ }^{11}$ In contrast branch-duct type IPMNs, in which there is no main duct involvement, have a much lower risk of malignant transformation, and in the absence of symptoms, or concerning features, usually undergo surveillance. ${ }^{11}$

Thus, the key question from a clinical perspective is whether a cyst is benign, has malignant potential, or harbors high-grade dysplasia or invasive carcinoma, as this dictates whether patients can be discharged, undergo surveillance, or require surgical intervention respectively (Figure 1). ${ }^{10,11}$ The diagnosis of pancreatic cysts, and assessment of risk of malignant transformation, incorporates a number of factors including clinical history, computed tomography (CT), magnetic resonance imaging (MRI) and endoscopic ultrasonography (EUS). EUS allows detailed visualization of the cyst (Figure 2a), and allows sampling of the cyst wall and fluid through EUS guided fine needle aspiration (EUSFNA) (Figure 2). This is a relatively low risk procedure with the most common adverse events being pancreatitis $(1.1 \%)$ and abdominal pain $(0.34 \%) .{ }^{12}$ The addition of EUS and EUS-FNA to either computer tomography (CT) or magnetic resonance imaging (MRI) has been shown to improve the overall accuracy for diagnosis of pancreatic cysts. ${ }^{13}$ Most of this additional benefit is from aspiration of cyst fluid which can be sent for a range of tests including cytology, biochemical and molecular testing. This chapter will focus on the biochemical and molecular tests, while cyst fluid cytology is discussed in depth in Chapter 9.

\section{BIOCHEMICAL TESTS FOR CYST FLUID}

\section{Carcinoembryonic antigen (CEA)}

A) Identifying IPMNs and MCNs-CEA is currently considered the most accurate marker for differentiating mucinous, from non-mucinous cysts, that is IPMNs and MCNs from other cyst types. The role of CEA was established in the multicenter, prospective cooperative study in 2004, which found that the accuracy of cyst fluid CEA was superior to EUS, cytology or other tumor markers including CA 72-4, CA 125, CA 19-9, and CA 15-3, for identifying mucinous cysts. ${ }^{14}$ However, since then several issues about CEA have arisen. The first is what is the optimal cutoff level to differentiate mucinous from non-mucinous cysts? The co-operative study identified the optimal level as $192 \mathrm{ng} / \mathrm{mL}$, which was associated with $75 \%$ sensitivity, and $84 \%$ specificity for differentiating between mucinous

Surg Pathol Clin. Author manuscript; available in PMC 2017 December 01. 
and non-mucinous cysts, and this level is most commonly used in clinical practice and publications. ${ }^{14}$ However, other groups have proposed alternative cutoffs. Using a higher cut off level of $>800 \mathrm{ng} / \mathrm{mL}$ was shown in a meta-analysis to increase the specificity to $98 \%$, although at the cost of lowering the sensitivity to $48 \% .{ }^{15}$ Similarly very low CEA levels of $<5 \mathrm{ng} / \mathrm{mL}$ has a very high specificity of $95 \%$, with $50 \%$ sensitivity, for non-mucinous cysts, such as serous cystadenomas and pseudocysts. ${ }^{15}$

The second issue is that although the initial studies were very promising, more recent data has suggested that cyst fluid CEA is imperfect at differentiating mucinous from nonmucinous cysts. The co-operative study found CEA had a high sensitivity and specificity (75\% and $84 \%$ respectively), for identifying mucinous cysts. ${ }^{14}$ In contrast, more recent studies have suggested a lower accuracy, with a large prospective study reporting a lower sensitivity and specificity of only $63 \%$ and $62 \%$ respectively. ${ }^{16}$ These findings were confirmed in meta-analysis of 18 studies with 1438 patients, where CEA had 63\% sensitivity and $88 \%$ specificity for identifying mucinous cysts. ${ }^{17}$

Finally, obtaining sufficient cyst fluid to assess CEA levels is often not possible, particularly in very small cysts, or if the fluid is very viscous. This issue was highlighted by a prospective European study in which CEA levels were obtained in only half of the cysts tested. ${ }^{18}$

\section{B) CEA is not helpful in identifying cysts with high-grade dysplasia or} invasive carcinoma-Some studies have suggested that a high cyst fluid CEA is associated with high-grade dysplasia or invasive cancer in IPMNs. However these studies were small, retrospective, and there was significant overlap between the CEA level in IPMNs with low-, or intermediate-grade dysplasia and those with high-grade dysplasia or invasive carcinoma. In contrast, much larger studies, including a prospective study and a meta-analysis, have found no association between CEA level and the presence of high-grade dysplasia or invasive carcinoma. ${ }^{14,19-21}$ Thus cyst fluid CEA level is not helpful in differentiating between benign and malignant pancreatic cysts.

\section{Amylase}

A) Excluding pseudocysts-Cyst fluid amylase level can be useful in excluding a pseudocyst from other types of pancreatic cysts. A large meta-analysis found a cyst fluid amylase level of $<250$ IU/L had a very high specificity of $98 \%$ for excluding a pseudocysts. ${ }^{15}$ In contrast, high cyst fluid amylase levels were found in numerous types of pancreatic cysts including SCAs, IPMNs and MCNs.

B) High amylase levels does not differentiate IPMNs from MCNs-One of the key questions is how to differentiate IPMNs from MCNs, as both have high cyst fluid CEA levels. On imaging, IPMNs communicate, or connect with the pancreatic duct, while MCNs have no communication. Theoretically, the communication between the main pancreatic duct and the cyst would cause IPMNs to have high cyst fluid amylase level, whereas MCNs should have a low amylase level. However, studies have shown that cyst fluid amylase level are similar in IPMNs and MCNs, and thus cannot be used to differentiate these two types of cysts. $^{22}$ 


\section{Other markers}

Several other tumor markers, including CA 72-4, CA 125, CA 19-9, and CA 15-3 have been evaluated. However, the diagnostic accuracy of these tumor makers has been found to be inferior to cyst fluid CEA in distinguishing mucinous from non-mucinous cysts in a number of studies. ${ }^{14,15}$ These markers are therefore not used in clinical practice.

\section{ACCURACY OF CYST FLUID MARKERS CURRENTLY USED IN CLINICAL PRACTICE}

As can be seen the currently available cyst fluid markers are imperfect at identifying cyst type, and cannot identify the presence of high-grade dysplasia or invasive carcinoma. This is highlighted by large surgical series, in which just over $20 \%$ of patients were found to have a benign cyst such as a SCA or a pseudocyst ${ }^{23}$, while almost $80 \%$ of resected branch duct IPMNs have either low, or intermediate-grade dysplasia ${ }^{24}$, and thus in retrospect, did not require surgical resection. Thus better markers are required.

\section{MOLECULAR MARKERS}

One of the problems with identifying mutations in pancreatic cysts is that the number of mutant alleles present is extremely low when compared with solid lesions, such as pancreatic ductal adenocarcinoma. ${ }^{25}$ However recent advances in molecular genetics, in particular the development of techniques such as FastSeq sequencing, mean that mutant alleles present very low levels can be identified. ${ }^{26}$ In the following section we discuss the potential of molecular markers in pancreatic cyst fluid. There are many other promising markers including mRNA and protein markers ${ }^{27-30}$, and a review of these markers is available elsewhere. ${ }^{31}$

In 2011, the group at Johns Hopkins lead by Bert Vogelstein analyzed the entire coding region of the genome of SCA, SPN, MCNs and IPMNs using whole-exome sequencing. ${ }^{25}$ There were two key findings: the first was that pancreatic cysts contained far fewer somatic mutations when compared with pancreatic ductal adenocarcinoma. The second was that each cyst type had a distinct mutational profile. SCAs contained a mutation in the von Hippel Lindau ( $V H L$ ) gene. SPNs were found to have a single mutation in the $C T N N B 1$ gene. Both IPMNs and MCNs had mutations in $K R A S$ or $R N F 43$, while IPMNs were found to harbor a mutation in $G N A S$, which was not identified in any other cyst type. This preliminary study was performed in pancreatic tissue, and in a subsequent study the group was able to show that the same mutations were identifiable in pancreatic cyst fluid. ${ }^{32}$ In a recent, multi-center study involving 130 patients all of whom had undergone surgical resection, the molecular marker panel was expanded to include a larger number of genetic mutations, as well as assessing loss of heterozygosity $(\mathrm{LOH})$ and aneuploidy. This study confirmed not only the ability of the molecular markers to accurately identify cyst type (Table 2), but also to identify the presence of high-grade dysplasia or invasive carcinoma in IPMNs, which was associated with the presence of a mutation in SMAD4, TP53, LOH chromosome 17 (RNF43 or TP53 loci), or aneuploidy in chromosomes 5p, 8p, 13q, 18q. In addition, the group developed a novel concept of combining molecular markers with clinical features to further improve the diagnostic accuracy of these markers which increased the sensitivity and 
specificity further. One of the interesting results in this paper was the ability of the molecular markers to correctly identified low risk cysts. The markers correctly classified 56 of the 62 SCA, and IPMNs with low- or intermediate-grade dysplasia. Thus, use of the molecular markers could potentially decrease the number of unnecessary surgical resections by $90 \%$. The use of molecular markers in pancreatic cysts has been assessed by other groups, who have also found very promising results. ${ }^{33-35}$ These, and the results from studies described previously are encouraging, however larger studies, incorporating other cysts types, are required before these molecular markers can be recommended in clinical practice. These studies are currently ongoing, and the results are expected to be available in 2016.

\section{Pancreatic juice}

One of the limitations of assessing pancreatic cyst fluid is that it requires EUS-FNA. Potential limitations are that a biopsy is invasive, only a portion of a cyst is sampled, and in cases of multiple pancreatic cysts, sampling of all cysts may not be feasible. An alternative approach is to analyze molecular markers in pancreatic juice collected from the duodenum. This avoids the potential adverse events of direct sampling of pancreatic fluid using fine needle aspiration, and in addition pancreatic juice may contain alterations present in multiple cysts throughout the pancreas, rather than a single cyst. The results from preliminary studies are promising. Kanda et al examined secretin-stimulated pancreatic juice collected from the duodenum during upper endoscopy, and identified $G N A S$ mutations in 66\% of IPMNs, which is similar to that observed in EUS aspirated cyst fluid. ${ }^{36}$ In a further development of this technique, the same authors examined the presence of TP53 mutations, which is a known tumor suppressor gene that has been implicated in progression of IPMNs, in duodenal samples of pancreatic juice. ${ }^{37}$ They found that TP53 mutations were detected in pancreatic juice in almost $70 \%$ of patients with pancreatic ductal adenocarcinoma, pancreatic intraepithelial neoplasias-3 or high-grade IPMN, but was not identified in individuals with benign cysts, or lower grades of dysplasia. These studies suggest the potential of use of pancreatic juice for detecting mutations present in pancreatic cysts, and this technique may prove complementary to cyst fluid aspiration in the diagnostic work-up of pancreatic cysts.

\section{Current clinical practice for the assessment of pancreatic cysts}

In our practice, we perform EUS-FNA of pancreatic cysts when it will alter management. Cyst fluid is currently sent for CEA and cytology. We also obtain cyst fluid amylase in cases that there is clinical suspicion of a pseudocyst. We await further studies to validate the accuracy of the molecular markers, and to determine how to optimally combine them with the currently available tests. If these studies duplicate the results discussed above, it is likely that molecular markers will become part, and may replace many of the currently used cyst fluid tests.

\section{Conclusion}

Pancreatic cyst fluid analysis provides important information that can be used to improve the diagnosis of pancreatic cysts. The results of cyst fluid analysis should be used in combination with clinical history and imaging to help guide management decisions. New 
molecular makers have shown promise, and are likely to become incorporated into clinical care in the near future.

\section{Abbreviations}

$\begin{array}{ll}\text { CA } & \text { carbohydrate antigen } \\ \text { CEA } & \text { carcinoembryonic antigen } \\ \text { CT } & \text { computed tomography } \\ \text { EUS } & \text { endoscopic ultrasound } \\ \text { FNA } & \text { fine-needle aspiration } \\ \text { IPMN } & \text { intraductal papillary mucinous neoplasm } \\ \text { LOH } & \text { loss of heterozygosity } \\ \text { MCN } & \text { mucinous cystic neoplasm } \\ \text { MRI } & \text { magnetic resonance imaging } \\ \text { PCN } & \text { pancreatic cystic neoplasms } \\ \text { SCA } & \text { serous cystadenoma } \\ \text { SPN } & \text { solid-pseudopapillary neoplasm } \\ \text { VHL } & \text { von Hippel Lindau }\end{array}$

\section{References}

1. Laffan TA, Horton KM, Klein AP, et al. Prevalence of unsuspected pancreatic cysts on MDCT. AJR Am J Roentgenol. 2008; 191:802-7. [PubMed: 18716113]

2. Lee KS, Sekhar A, Rofsky NM, et al. Prevalence of incidental pancreatic cysts in the adult population on MR imaging. The American journal of gastroenterology. 2010; 105:2079-84. [PubMed: 20354507]

3. Gaujoux S, Brennan MF, Gonen M, et al. Cystic lesions of the pancreas: changes in the presentation and management of 1,424 patients at a single institution over a 15-year time period. J Am Coll Surg. 2011; 212:590-600. discussion 600-3. [PubMed: 21463795]

4. Lennon AM, Wolfgang C. Cystic neoplasms of the pancreas. J Gastrointest Surg. 2013; 17:645-53. [PubMed: 23340991]

5. Jaïs B, Rebours V, Malleo G, et al. Pancreatic Serous Cystadenoma Related Mortality Is Nil. Results of a Multinational Study Under the Auspices of the International Association of Pancreatology and the European Pancreatic Club. Gut. 2015 [Epub ahead of print].

6. Law JK, Ahmed A, Singh VK, et al. A systematic review of solid-pseudopapillary neoplasms: are these rare lesions? Pancreas. 2014; 43:331-7. [PubMed: 24622060]

7. Jang KT, Park SM, Basturk O, et al. Clinicopathologic Characteristics of 29 Invasive Carcinomas Arising in 178 Pancreatic Mucinous Cystic Neoplasms With Ovarian-type Stroma: Implications for Management and Prognosis. Am J Surg Pathol. 2015; 39:179-87. [PubMed: 25517958]

8. Yamao K, Yanagisawa A, Takahashi K, et al. Clinicopathological features and prognosis of mucinous cystic neoplasm with ovarian-type stroma: a multi-institutional study of the Japan pancreas society. Pancreas. 2011; 40:67-71. [PubMed: 20924309] 
9. Baker ML, Seeley ES, Pai R, et al. Invasive mucinous cystic neoplasms of the pancreas. Exp Mol Pathol. 2012; 93:345-9. [PubMed: 22902940]

10. Del Chiaro M, Verbeke C, Salvia R, et al. European experts consensus statement on cystic tumours of the pancreas. Dig Liver Dis. 2013; 45:703-11. [PubMed: 23415799]

11. Tanaka M, Fernandez-Del Castillo C, Adsay V, et al. International consensus guidelines 2012 for the management of IPMN and MCN of the pancreas. Pancreatology. 2012; 12:183-97. [PubMed: 22687371]

12. Wang KX, Ben QW, Jin ZD, et al. Assessment of morbidity and mortality associated with EUSguided FNA: a systematic review. Gastrointest Endosc. 2011; 73:283-90. [PubMed: 21295642]

13. Khashab MA, Kim K, Lennon AM, et al. Should we do EUS/FNA on patients with pancreatic cysts? The incremental diagnostic yield of EUS over CT/MRI for prediction of cystic neoplasms. Pancreas. 2013; 42:717-21. [PubMed: 23558241]

14. Brugge WR, Lewandrowski K, Lee-Lewandrowski E, et al. Diagnosis of pancreatic cystic neoplasms: a report of the cooperative pancreatic cyst study. Gastroenterology. 2004; 126:1330-6. [PubMed: 15131794]

15. van der Waaij LA, van Dullemen HM, Porte RJ. Cyst fluid analysis in the differential diagnosis of pancreatic cystic lesions: a pooled analysis. Gastrointest Endosc. 2005; 62:383-9. [PubMed: 16111956]

16. Al-Haddad M, Dewitt J, Sherman S, et al. Performance characteristics of molecular (DNA) analysis for the diagnosis of mucinous pancreatic cysts. Gastrointest Endosc. 2014; 79:79-87. [PubMed: 23845445]

17. Anand N, Sampath K, Wu BU. Cyst features and risk of malignancy in intraductal papillary mucinous neoplasms of the pancreas: a meta-analysis. Clinical gastroenterology and hepatology: the official clinical practice journal of the American Gastroenterological Association. 2013; 11:913-21. quiz e59-60. [PubMed: 23416279]

18. de Jong K, Poley JW, van Hooft JE, et al. Endoscopic ultrasound-guided fine-needle aspiration of pancreatic cystic lesions provides inadequate material for cytology and laboratory analysis: initial results from a prospective study. Endoscopy. 2011; 43:585-90. [PubMed: 21611945]

19. Cizginer S, Turner BG, Bilge AR, et al. Cyst fluid carcinoembryonic antigen is an accurate diagnostic marker of pancreatic mucinous cysts. Pancreas. 2011; 40:1024-8. [PubMed: 21775920]

20. Park WG, Mascarenhas R, Palaez-Luna M, et al. Diagnostic performance of cyst fluid carcinoembryonic antigen and amylase in histologically confirmed pancreatic cysts. Pancreas. 2011; 40:42-5. [PubMed: 20966811]

21. Ngamruengphong S, Bartel MJ, Raimondo M. Cyst carcinoembryonic antigen in differentiating pancreatic cysts: a meta-analysis. Dig Liver Dis. 2013; 45:920-6. [PubMed: 23790480]

22. Thornton GD, McPhail MJ, Nayagam S, et al. Endoscopic ultrasound guided fine needle aspiration for the diagnosis of pancreatic cystic neoplasms: a meta-analysis. Pancreatology. 2013; 13:48-57. [PubMed: 23395570]

23. Valsangkar NP, Morales-Oyarvide V, Thayer SP, et al. 851 resected cystic tumors of the pancreas: a 33-year experience at the Massachusetts General Hospital. Surgery. 2012; 152:S4-12. [PubMed: 22770958]

24. Sahora K, Mino-Kenudson M, Brugge W, et al. Branch duct intraductal papillary mucinous neoplasms: does cyst size change the tip of the scale? A critical analysis of the revised international consensus guidelines in a large single-institutional series. Ann Surg. 2013; 258:46675. [PubMed: 24022439]

25. Wu J, Jiao Y, Dal Molin M, et al. Whole-exome sequencing of neoplastic cysts of the pancreas reveals recurrent mutations in components of ubiquitin-dependent pathways. Proc Natl Acad Sci USA. 2011; 108:21188-93. [PubMed: 22158988]

26. Springer S, Wang Y, Dal Molin M, et al. A Combination of Molecular Markers and Clinical Features Improve the Classification of Pancreatic Cysts. Gastroenterology. 2015; 149:1501-10. [PubMed: 26253305]

27. Yip-Schneider MT, Wu H, Dumas RP, et al. Vascular endothelial growth factor, a novel and highly accurate pancreatic fluid biomarker for serous pancreatic cysts. J Am Coll Surg. 2014; 218:60817. [PubMed: 24491241] 
28. Das KK, Xiao H, Geng X, et al. mAb Das-1 is specific for high-risk and malignant intraductal papillary mucinous neoplasm (IPMN). Gut. 2014; 63:1626-34.

29. Matthaei H, Wylie D, Lloyd MB, et al. miRNA biomarkers in cyst fluid augment the diagnosis and management of pancreatic cysts. Clin Cancer Res. 2012; 18:4713-24. [PubMed: 22723372]

30. Zikos T, Pham K, Bowen R, et al. Cyst Fluid Glucose is Rapidly Feasible and Accurate in Diagnosing Mucinous Pancreatic Cysts. Am J Gastroenterol. 2015; 110:909-14. [PubMed: 25986360]

31. Maker AV, Carrara S, Jamieson NB, et al. Cyst fluid biomarkers for intraductal papillary mucinous neoplasms of the pancreas: a critical review from the international expert meeting on pancreatic branch-duct-intraductal papillary mucinous neoplasms. J Am Coll Surg. 2015; 220:243-53. [PubMed: 25592469]

32. Wu J, Matthaei H, Maitra A, et al. Recurrent GNAS mutations define an unexpected pathway for pancreatic cyst development. Sci Transl Med. 2011; 3:92ra66.

33. Amato E, Molin MD, Mafficini A, et al. Targeted next-generation sequencing of cancer genes dissects the molecular profiles of intraductal papillary neoplasms of the pancreas. J Pathol. 2014; 233:217-27. [PubMed: 24604757]

34. Singhi AD, Nikiforova MN, Fasanella KE, et al. Preoperative GNAS and KRAS Testing in the Diagnosis of Pancreatic Mucinous Cysts. Clin Cancer Res. 2014

35. Furukawa T, Kuboki Y, Tanji E, et al. Whole-exome sequencing uncovers frequent GNAS mutations in intraductal papillary mucinous neoplasms of the pancreas. Sci Rep. 2011; 1:161. [PubMed: 22355676]

36. Kanda M, Knight S, Topazian MD, et al. Mutant GNAS detected in duodenal collections of secretin-stimulated pancreatic juice indicates the presence or emergence of pancreatic cysts. Gut. 2012

37. Kanda M, Sadakari Y, Borges M, et al. Mutant TP53 in Duodenal Samples of Pancreatic Juice from Patients with Pancreatic Cancer or High-Grade Dysplasia. Clin Gastroenterol Hepatol. 2012 


\section{Key points}

- Pancreatic cysts are common, and are incidentally identified in between $2 \%$ to $13 \%$ of individuals undergoing cross sectional imaging.

- $\quad$ Cyst fluid carcinoembryonic antigen (CEA) is currently considered the most accurate marker for differentiating mucinous (IPMNs and MCNs) from non-mucinous cysts, however recent studies suggest that its accuracy is approximately $65 \%$.

- $\quad$ New molecular markers in cyst fluid have shown promise in differentiating SCAs, SPNs, MCNs and IPMNs, and identifying the presence of high-grade dysplasia or invasive adenocarcinoma. 


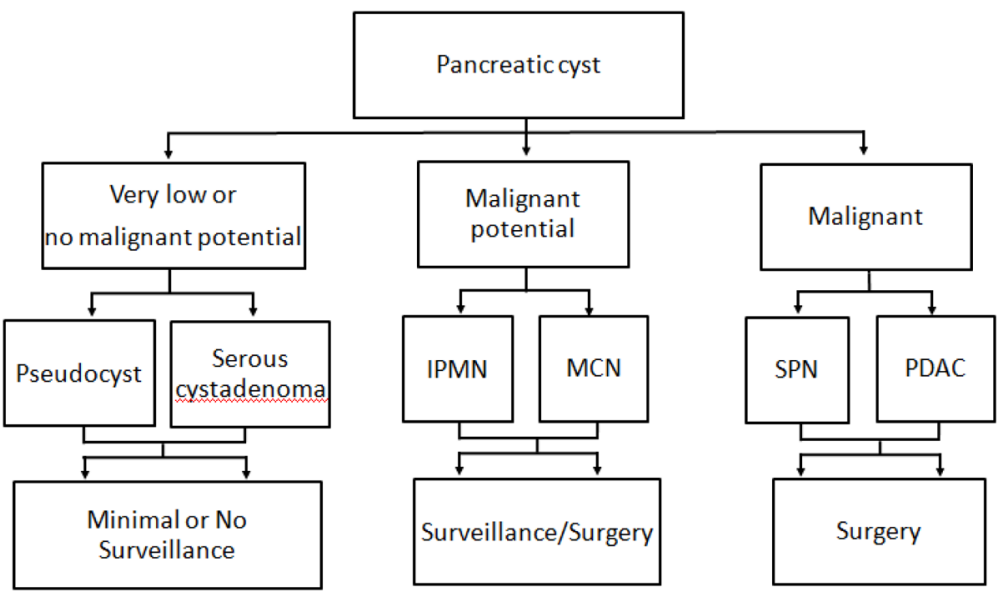

Figure 1.

Algorithm for the management of pancreatic cysts 


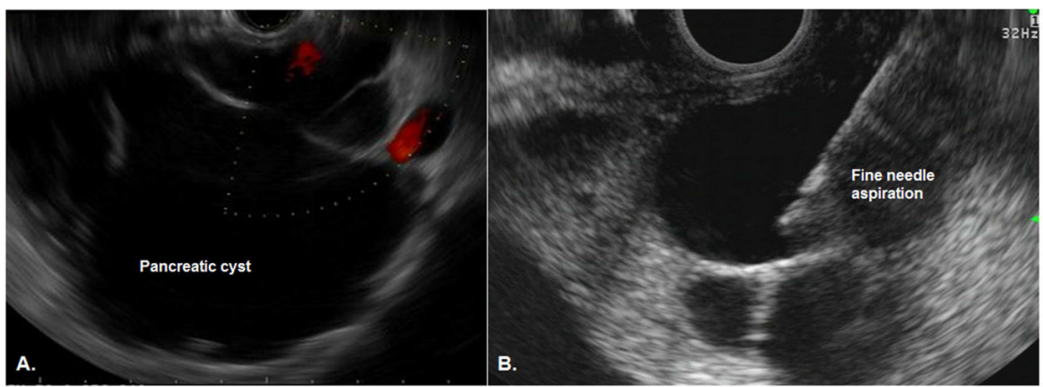

Figure 2.

Endoscopic ultrasound of a pancreatic cyst. A) EUS image of a pancreatic cyst with thin septations. B) EUS-guided fine needle aspiration. The needle (arrow) can be seen within the center of the cyst. 


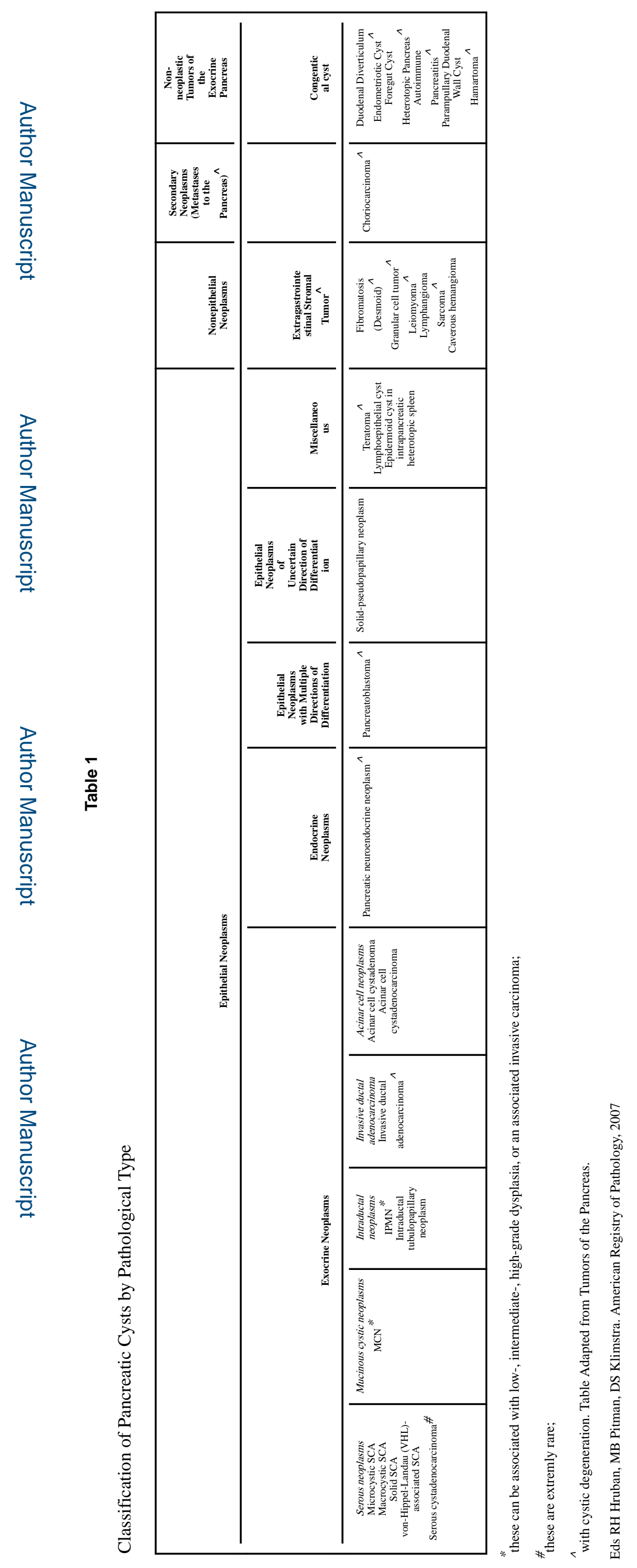




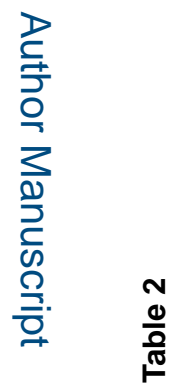

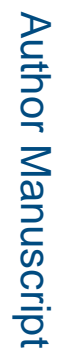

\begin{tabular}{|c|c|c|c|c|c|}
\hline \multirow{4}{*}{ 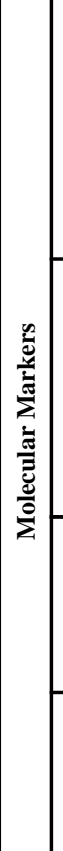 } & 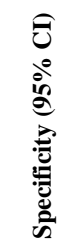 & 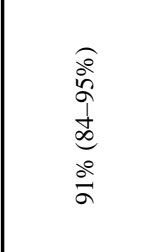 & 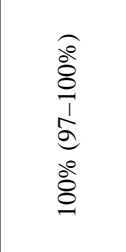 & 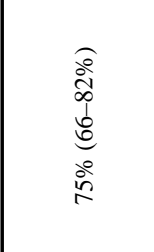 & 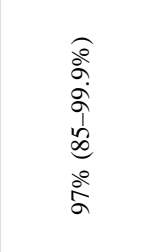 \\
\hline & 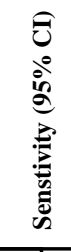 & 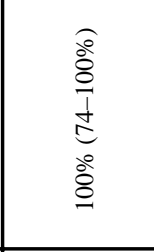 & 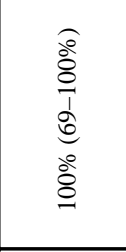 & 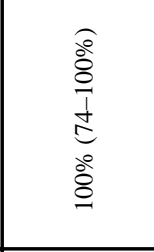 & $\begin{array}{l}0 \\
0 \\
0 \\
0 \\
0 \\
b \\
0 \\
0 \\
0 \\
0\end{array}$ \\
\hline & 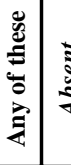 & 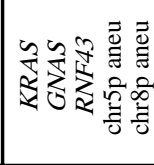 & 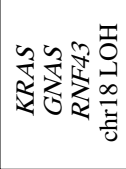 & 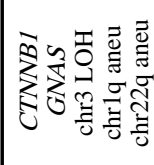 & 苂 \\
\hline & 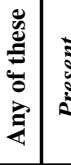 & $\begin{array}{l}\frac{T}{0} \\
\frac{m}{0}\end{array}$ & 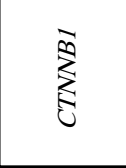 & 弚 & 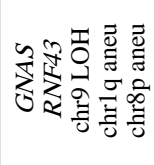 \\
\hline & 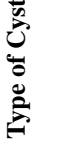 & త్ర & $\frac{Z}{\omega}$ & $\sum_{\Sigma}^{Z}$ & $\sum_{E}^{Z}$ \\
\hline
\end{tabular}

Surg Pathol Clin. Author manuscript; available in PMC 2017 December 01. 